\title{
CARDIAC LESIONS IN THIAMIN DEFICIENCY
}

\author{
BY \\ J. FRANK PANTRIDGE \\ From the Department of Pathology, Queen's University, and Royal Victoria Hospital, Belfast \\ Received July 22, 1948
}

Experience of beriberi occurring among British and Australian prisoners of war indicated that heart block was not infrequent.

There is no general agreement about the effect of thiamin deficiency on the heart, and in particular on cardiac conduction. The only electrocardiographic abnormality noted by Aalsmeer and Wenckebach (1929) was a shortening of the P-R interval. Keefer (1930) in 29 cases of beriberi noted no characteristic cardiographic change, though cardiac conduction was sometimes slightly altered: 15 of the 29 cases had evidence of cardiac insufficiency; these showed enlargement of the right auricle, right ventricle, pulmonary conus, and pulmonary artery. Jolliffe (1939) in experimental thiamin deficiency found cardiographic changes in 2 of 5 human volunteers: in one, sinus arrhythmia, sinus arrest, and inversion of T III appeared after 11 days of deficiency, and in a second inversion of T III appeared after 8 days of deficiency. The changes reported by Weiss and Wilkins (1937) and by Dustin et al. (1939) included tachycardia, prolongation of electric systole, low voltage complexes, and flattening or inversion of $T$ waves. Dock (1940) recorded 5 cases of idiopathic cardiac hypertrophy with mural thrombi thought to result from thiamin deficiency, in 4 of whom there was disturbance of conduction-right bundle branch block in 3 and latent A-V block in 1 case. Casanova (1946) observed flat bifid P waves, prolongation of the $\mathbf{P}-\mathbf{R}$ interval, and auricular fibrillation (once) in beriberi.

Most accounts of the pathology of the heart in beriberi have been limited to a description of the macroscopic abnormalities. It is uncertain whether the enlargement of the right side of the heart is due to dilatation alone or to dilatation combined with hypertrophy.

Weiss and Wilkins (1937) found that the weight of the heart was generally normal and that there was a moderate dilatation of the right ventricle. Wenckebach (1934) and Weiss and Wilkins (1937) observed a "hydropic" degeneration of the muscle fibres.
Disturbances of A-V conduction are not mentioned in most clinical accounts of beriberi and lesions affecting the specialized muscle of the conducting system have not been noted on histological examination. Thus Blankenhorn (1945) gave as the first of the criteria for the diagnosis of beriberi heart disease "an enlarged heart with normal sino-auricular rhythm."

As there is no general recognition of the appearance of conduction defects in human thiamin deficiency it was thought advisable to record the clinical impression of its not infrequent occurrence. In the light of our clinical experience it was considered that analysis of the effects upon cardiac conduction of prolonged severe thiamin deficiency in animals would be of value and should determine whether the changes present had a functional or organic basis.

\section{EXPERIMENTAL METHODS}

Pigs were used since they are known to be the animals most susceptible to thiamin deficiency. The animals were obtained when five weeks old. The dietetic method was largely that of Wintrobe (1942). This consists of feeding a basal vitamin-free diet. The basal diet in this experiment consisted of sugar, crude casein and cooking fat, and provided approximately 150 calories per $\mathrm{kg}$. of body weight daily. The daily supplements added to this diet were those used by Wintrobe (1943). With the exception of thiamin which was entirely omitted, these supplements contained synthetic vitamins and minerals in quantities known to be adequate to maintain the normal health and growth of the animals.

Four pigs were kept on this diet. Two additional pigs used as controls were given the same basal vitamin and mineral supplement, and in addition these control pigs were given $0.51 \mathrm{mg}$. of thiamin hydrochloride per $\mathrm{kg}$. of body weight daily.

Frequent electrocardiograms were obtained from all six animals. Three standard leads and one chest lead CF 4 were used. The normal variations in the 


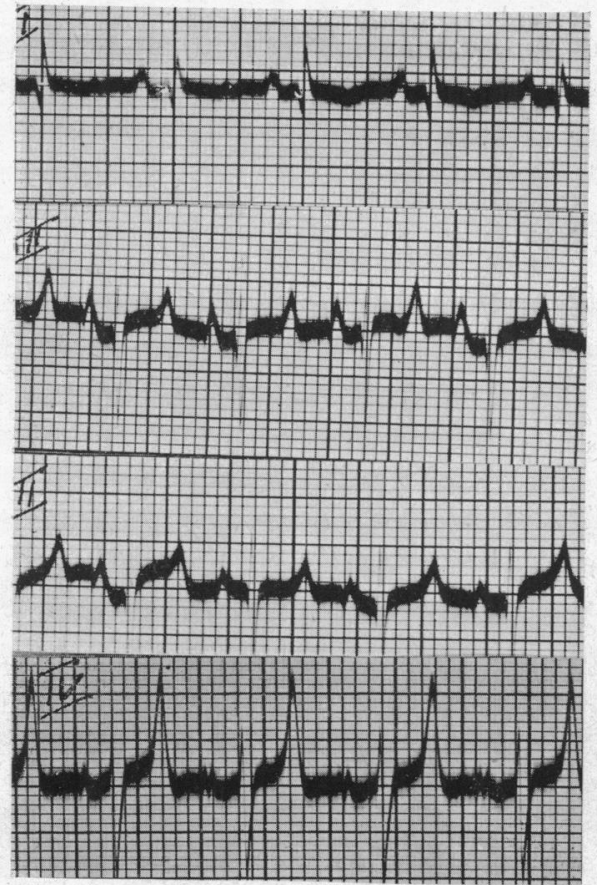

FIG. 1.-Normal pig. Standard limb leads and CF 4. The T wave in CF 4 is invariably upright.

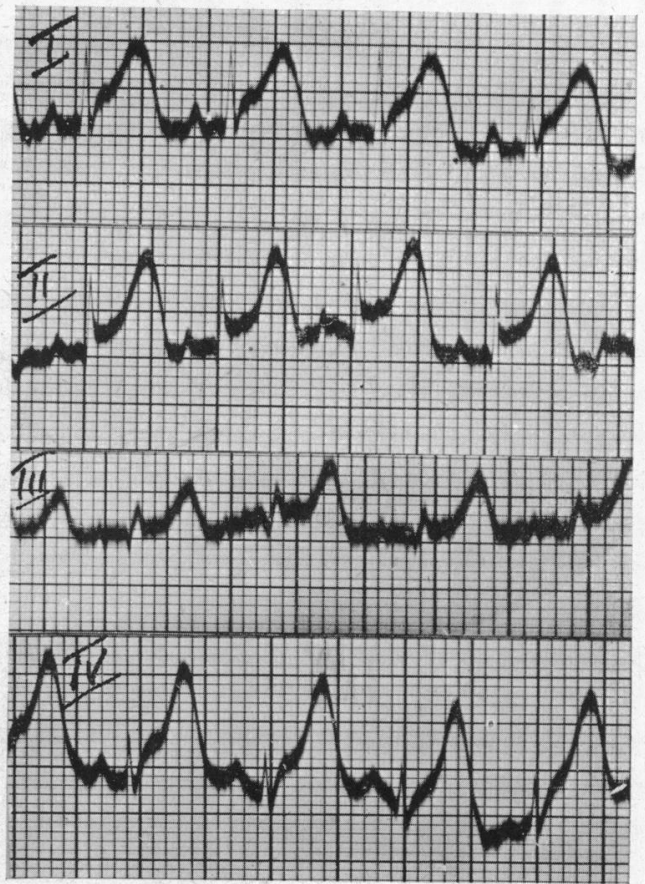

Fig. 2.-Pig No. 1. Standard leads and CF 4 on 73rd day of deficiency, 24 hours before death. Huge $T$ waves and elevation of $S-T$ segment in all leads.

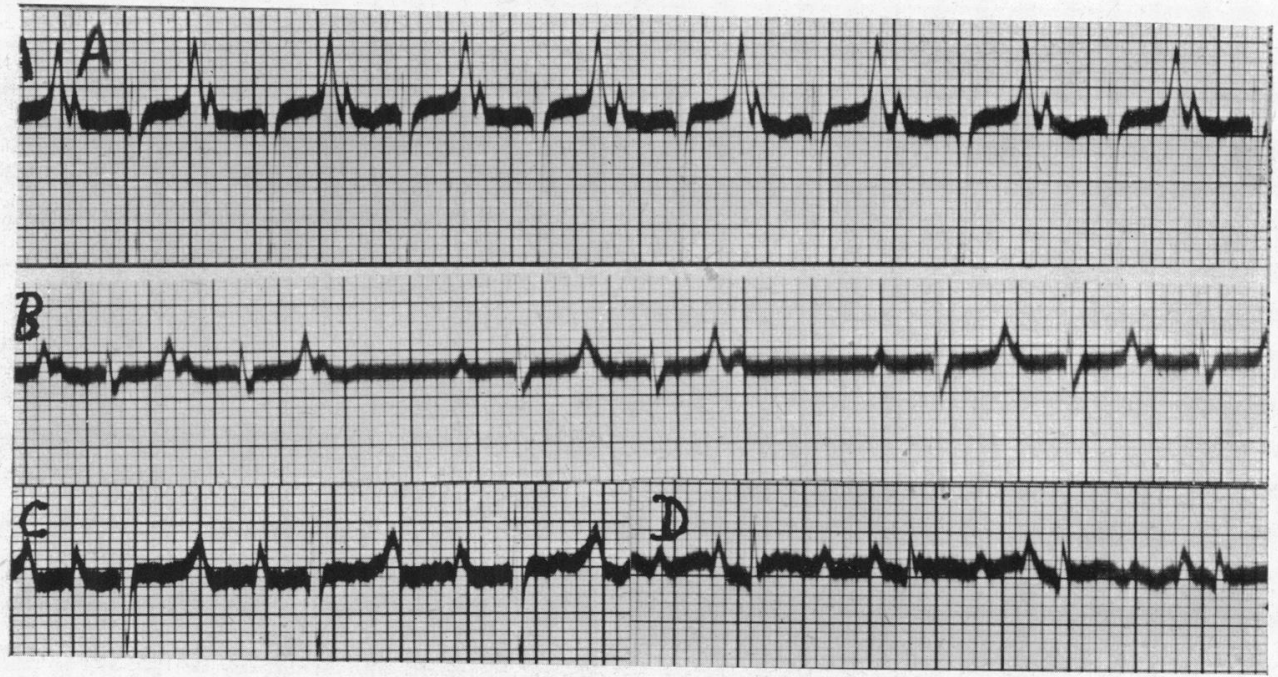

FIG. 3.-Pig No. 1. (A) Lead II: 40th day of deficiency, showing first degree of A-V block. P-R interval 0.18 sec. (B) Lead I, recorded 4 hours later showing second degree A-V block. (C) Lead II: 41st day of deficiency, 24 hours after injection of $2.5 \mathrm{mg}$. thiamin. P-R interval 0.16 sec. (D) Lead II: 45 th day of deficiency. P-R interval has returned to within normal limits. 
pig were established at the beginning of the experiment. The average heart rate was 143 , and the lowest rate recorded was 130 . The rhythm in the normal pig was invariably regular, and in no instance was sinus arrhythmia recorded. The P-R interval varied from 0.06 to $0.10 \mathrm{sec}$. usually 0.08 to $0 \cdot 10$. The QRS varied from 0.04 to $0.08 \mathrm{sec}$.
T I was frequently inverted and T II and III were usually upright. Inversion of $\mathrm{T}$ in $\mathrm{CF} 4$ was not seen in the normal pig (Fig. 1).

\section{RESUlts}

Control pigs maintained on this regime with adequate daily thiamin allowance remained healthy.

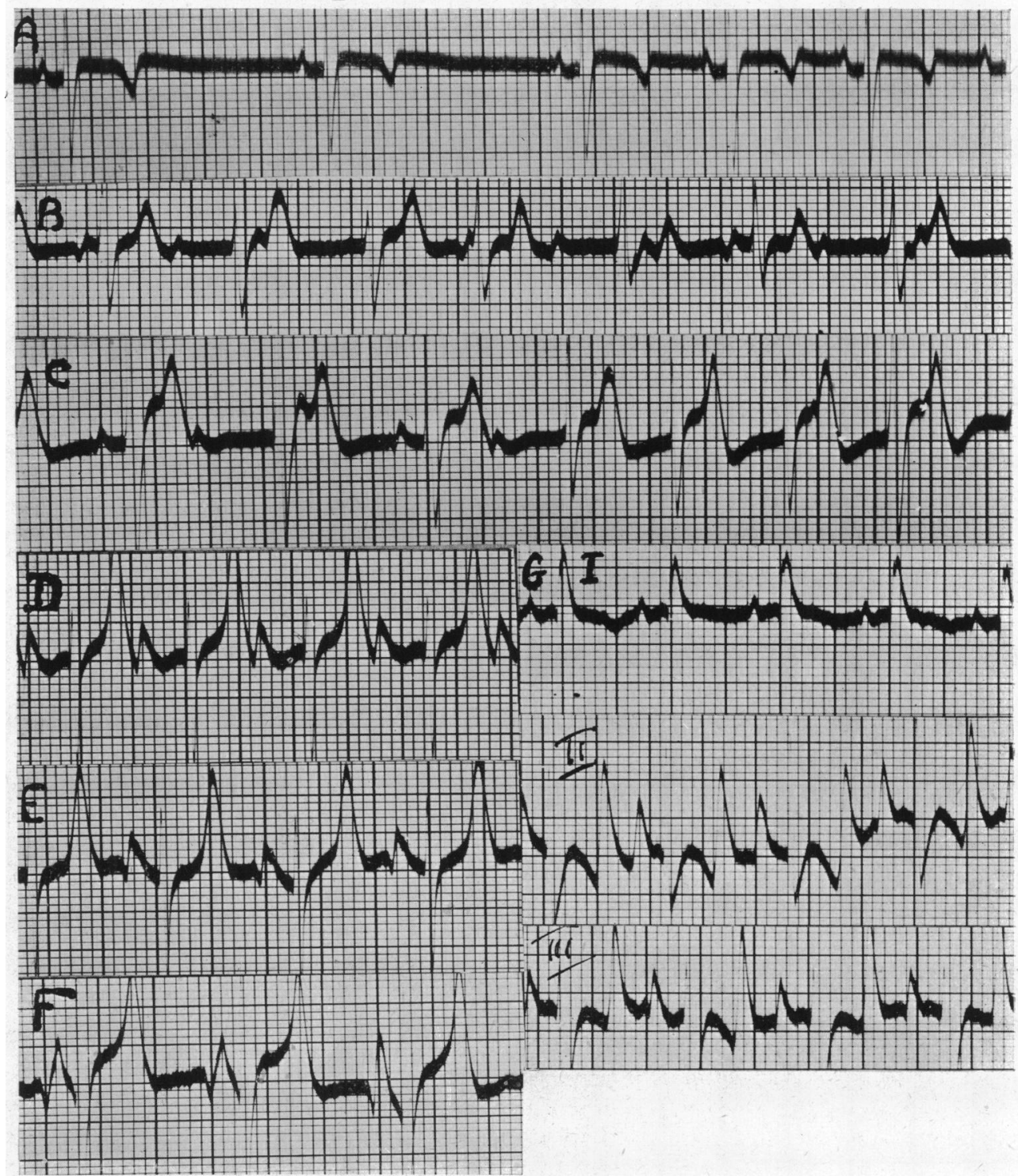

FIG. 4.-Pig No. 2. (A) Lead IV: 49th day of deficiency showing sinus arrest and inversion of T IV. (B) and (C) Leads I and IV: 77th day of deficiency showing complete heart block and elevation of S-T segment in lead IV. (D) Lead II: 77th day, one hour after injection of 2.5 mg. of $B_{1}$. First degree block, P-R interval $0 \cdot 18$ sec. (E) Lead II: 78th day, 24 hours after thiamin, $P-R$ interval $0 \cdot 16$ sec. (F) 80 th day $P-R$ interval within normal limits. (G) Standard leads: 99th day; left bundle branch block, the QRS interval exceeds 0.08 sec. 
Frequent electrocardiograms showed no deviation from the normal. These control pigs were slaughtered on the 84th experimental day and their hearts subjected to detailed histological examination. Numerous sections from all four chambers of the heart, and multiple sections from the interauricular and interventricular septa failed to show any histological abnormality.

The four pigs deprived of thiamin developed anorexia and occasional vomiting between the 30th and 40th days, and thereafter at intervals. Three of the animals died from thiamin deficiency. One was sacrificed after 157 days. All four developed disturbances of A-V conduction (Fig. 3; 4, 5, and 6). The animals were acutely ill at the time of appearance of A-V block. One animal (No. 3) died with complete block.

Death of the others showing block was prevented by a single intramuscular injection of $2.5 \mathrm{mg}$. of thiamin hydrochloride. The time of appearance of the conduction disturbance, the degree of block, the response of the block to thiamin, and the duration of survival on the thiamin deficient regime are indicated in the table. From this it is seen that the sinus arrest, and inversion of CF 4 (Fig. 4, 5, and 6). These changes appeared between the 40th and 60th days. Sinus block was not affected by atropine.

Normal cardiograms were recorded for some time following the treatment of A-V block with thiamin. Pig No. 2 developed left bundle branch block 22 days after thiamin treatment of complete block. The other two animals failed to develop a second episode of block but before death showed marked elevation of the $\mathrm{S}-\mathrm{T}$ segments and huge $\mathrm{T}$ waves on all four leads (Fig. 2).

Post-mortem examination of these animals showed no evidence of subcutaneous œdema. Excess of fluid was found in the pericardial sacs. In one animal (No. 4) this amounted to $170 \mathrm{ml}$. (6 oz.). No excess of fluid was apparent in the other body cavities. The hearts showed dilatation of the right auricle and of the right ventricle, particularly in the region of the pulmonary conus. Apart from the heart of animal No. 2 which showed numerous subendocardial hæmorrhages, considered incidental to the shock of killing, there was no macroscopic abnormality in the muscle, valves or endocardium. The hearts formed 0.51 to 0.59 per

TABLE

Development of Heart Block with Thiamin Deficiency

\begin{tabular}{|c|c|c|c|c|c|c|}
\hline \multicolumn{3}{|c|}{ Animal } & $\begin{array}{l}\text { Day of deficiency } \\
\text { at the appearance } \\
\text { of block }\end{array}$ & Degree of block & $\begin{array}{l}\text { P-R interval: } \\
\text { (a) } 1 \mathrm{hr} \text {. (b) } 24 \mathrm{hrs.} \\
\text { (c) } 48 \mathrm{hrs.} \mathrm{after} \mathrm{in-} \\
\text { jection of thiamin }\end{array}$ & Day of death \\
\hline No. $1 .$. & .. & .. & $\begin{array}{l}\text { 40th } \\
\text { (1) Morning. } \\
\text { (2) Afternoon }\end{array}$ & $\begin{array}{l}\text { Latent } P-R, 0.2 \mathrm{sec} . \\
\text { 2nd degree }\end{array}$ & $\begin{array}{l}\text { (b) } 0.16 \mathrm{sec} \\
\text { (c) } 0.1 \mathrm{sec}\end{array}$ & 74th \\
\hline No. $2 .$. & .. &.. & $\begin{array}{l}\text { 77th } \\
99 \text { th }\end{array}$ & $\begin{array}{l}\text { Complete } \\
\text { Left } \\
\text { bundle branch }\end{array}$ & $\begin{array}{l}\text { (a) } 0.18 \mathrm{sec} . \\
\text { (b) } 0 \cdot 16 \mathrm{sec} . \\
\text { (c) } 0 \cdot 1 \mathrm{sec} .\end{array}$ & Sacrificed $157^{\text {th }}$ \\
\hline No. 3.. & .. & .. & $\begin{array}{l}\text { 63rd } \\
64 \text { th }\end{array}$ & $\begin{array}{l}\text { 2nd degree } \\
\text { Complete }\end{array}$ & - & 64th \\
\hline No. 4 .. & .. &.. & 58th to 63 rd & $\begin{array}{l}\text { Latent P-R, 0.14- } \\
0.15 \mathrm{sec} .\end{array}$ & (b) $0.08 \mathrm{sec}$ & 116th \\
\hline
\end{tabular}

administration of thiamin to three of the animals during the episode of block resulted in return of normal A-V induction within 48 hours. Following thiamin treatment the animals were maintained on the deficient diet.

With the exception of pig No. 1 in which heart block occurred on the 40th day, the animals showed cardiographic changes prior to the development of block. These consisted of marked bradycardiarates as low as 65 were recorded - sinus arrhythmia, cent of the body weight as opposed to the normal 0.3 to 0.4 per cent.

Sections for histological examination were obtained from the anterior and posterior walls of each auricle, from the auricular appendages, the interauricular septa and from the anterior, lateral, and posterior walls of each ventricle. The interventricular septa were blocked in series and multiple sections from each examined.

Lesions were found in the auricles, the auricular 


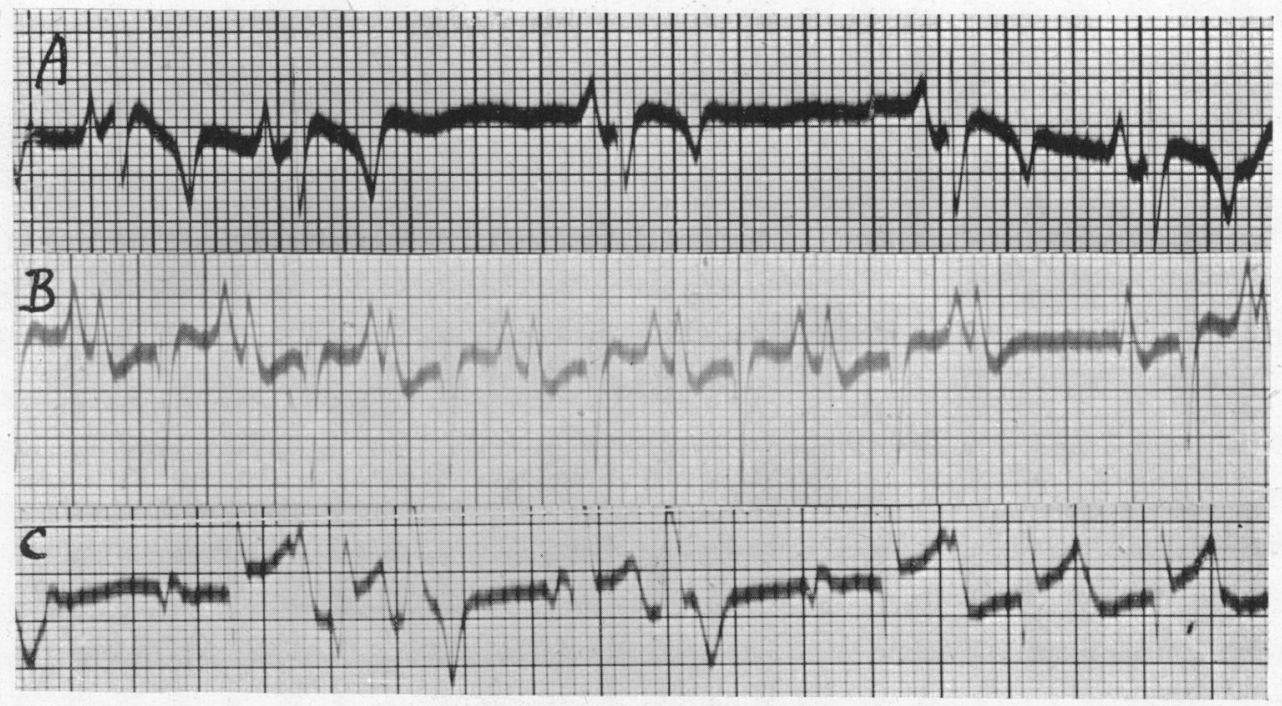

FIG. 5.-Pig No. 3. (A) Lead IV: 52nd day of deficiency, showing sinus block and inversion of T IV. (B) Lead II: 63rd day of deficiency, showing second degree A-V block. (C) Lead I: 65th day, half-an-hour before death, showing complete heart block.

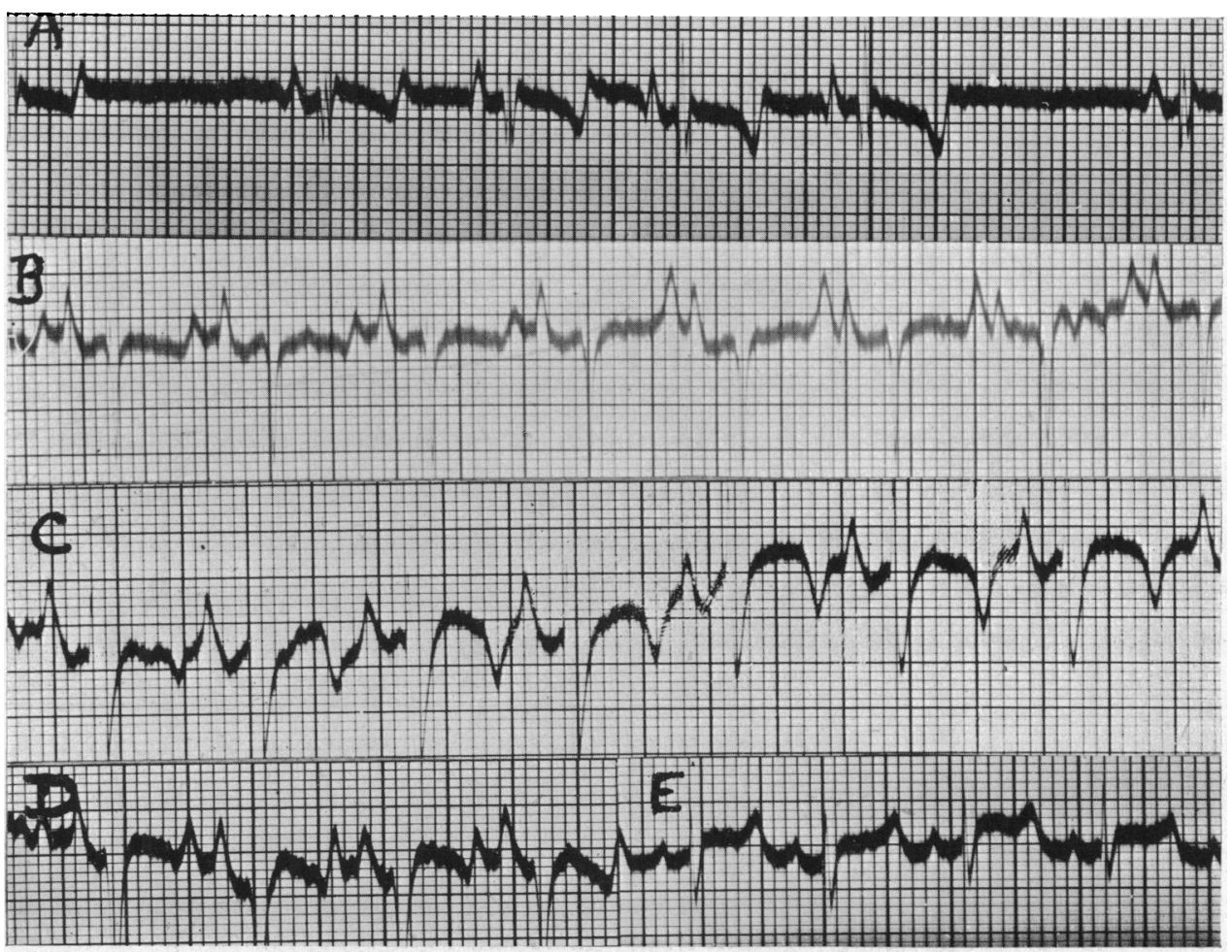

FIG. 6.-Pig No. 4. (A) Lead II: 52nd day of deficiency, showing sinus arrest. (B) and (C) Leads II and IV: 62 nd day of deficiency, showing first degree A-V block (P-R $0.16 \mathrm{sec}$.) and inversion of TIV. (D) and (E) leads II and IV, following the administration of thiamin. The $\mathbf{P}-\mathbf{R}$ interval is within normal limits. T IV is upright. 
appendages and the auricular septa in all four animals. These consisted of areas where muscle fibres had disappeared leaving an œdematous reticulum the interstices of which frequently contained an eosinophilic and protein-like fluid. A mononuclear cellular infiltration was seen in the areas of muscle damage and in the interstitial tissue in relation to them. Changes of a more acute character appeared in the left auricle and auricular septum of animal No. 4. Here were seen areas of active muscle necrosis associated with a leucocytic exudate and gross extravasation of red cells (Fig. 7).

Healing and healed lesions in the auricles of three of the animals were minimal. However in pig No. 2 which survived 157 days, areas of replacement of muscle by granulation tissue or fibrous tissue were numerous. Some sections from the left auricle of this animal showed replacement of the majority of the muscle fibres by fibrous tissue (Fig. 8).

The microscopic auricular lesions old and recent, were in all the animals most marked in the left auricle and auricular septum. In sections taken from the ventricular septum and ventricular walls it was possible to demonstrate the bundles of His, its main branches, and the terminal subendocardial and intra-myocardial ramifications of the conducting system.

The conducting system in the pig differs markedly from that in man. Glomset and Glomset (1940) have shown that in man Purkinje cells do not exist

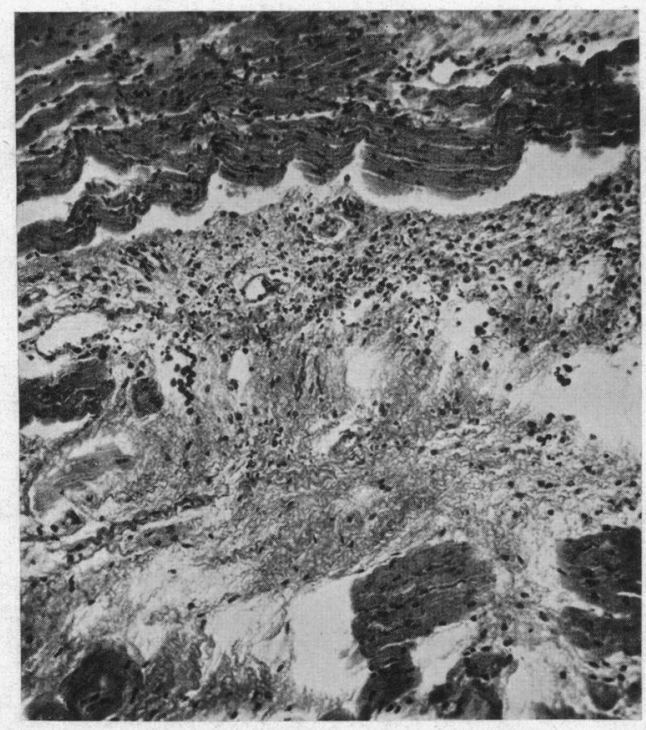

FIG. 7.-Pig No. 4. Interauricular septum. There is an acute hæmorrhagic necrosis of muscle fibres. Magnification $\times 210$. in the main bundle nor in the upper part of the right branch. The cells that are described as Purkinje elements in the left branch and lower part of the right branch differ markedly from those found in ungulates. They do not form a network, are found only subendocardially, and have never been recognized within the myocardium. Cells closely resembling those described by Purkinje in the heart of the sheep are seen in the bundle of His, and its main branches in the pig. Similar cells are seen forming a subendocardial network in the ventricles and penetrating deeply into the ventricular myocardium. These cells are round, oval, or band-like in shape with distinct cell outline and measuring from $24 \mu$ to $66 \mu$ in diameter. The cytoplasm is eosinophilic staining irregularly and shows a perinuclear clear zone. The myofibrils of the cells are irregular in their arrangement. The cells occasionally show a double nucleus; more commonly they have a single elongated nucleus which varies in its position in the cell. In elongated cells the long axis of the nucleus tends to be arranged at right angles to the long axis of the cell.

The ventricular lesions in these animals were confined almost entirely to the Purkinje system. In animal No. 3 which had at the time of death complete heart block, marked recent degenerative changes were found in many of the cells of the conducting system. These degenerate cells had shrunken from their surrounding supporting reticulum, their

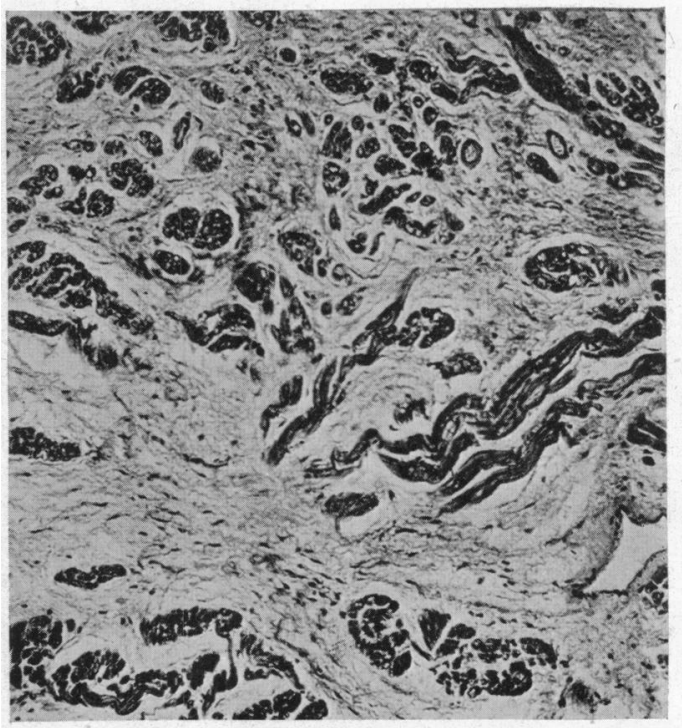

FIG. 8.-Pig No. 2. Section from the right auricle showing the healed auricular lesions. There is marked fibrous replacement of muscle. Magnification $\times 90$. 


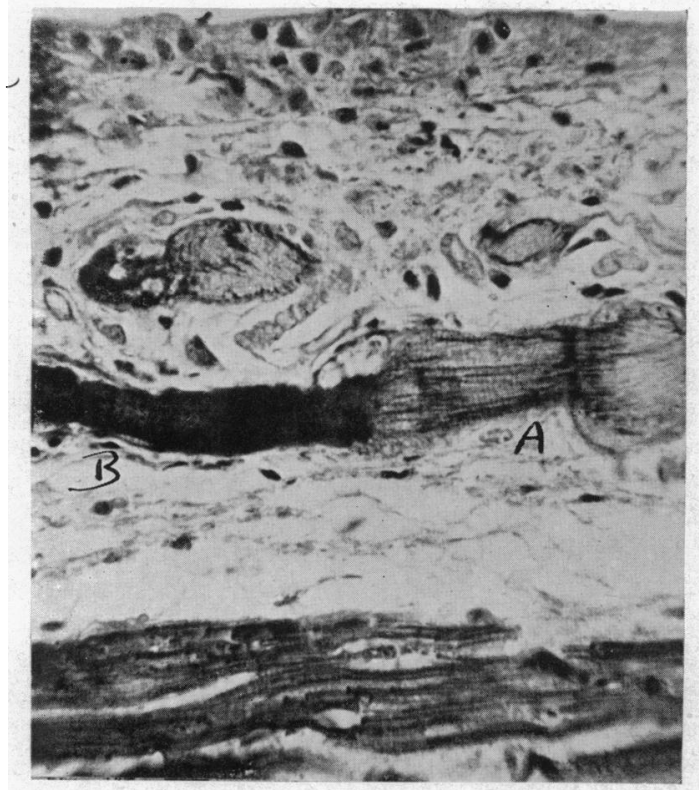

FIG. 9.-Pig No. 3. Subendocardial Purkinje cells. (A) Normal cells. The myofibrils are distinct. (B) Necrotic cell. The cell stains deeply. The myofibrils are no longer apparent. Magnification $\times 375$.

cytoplasm had become deeply eosinophilic and of a structureless hyaline appearance. The myofibrils were no longer distinguished (Fig. 9). The nuclei showed pyknotic change.

More than half the cells in the main bundle (Fig. 10) and many of the cells in the main bundle branches were involved in this acute hyaline necrosis (Fig. 11). One-third to one-half of the subendocardial and intra-myocardial Purkinje cells were affected. A mononuclear cellular reaction was found surrounding many of these degenerate subendocardial and intra-myocardial cells. Cellular reaction was much less evident in relation to the damaged cells in the bundle of $\mathrm{His}$ and its main branches.

Sections from the main bundles of pigs No. 1 and 4-these animals had survived episodes of heart block-showed in comparison with sections from the bundles of normal animals a complete disappearance of a considerable number of Purkinje cells and their replacement by connective tissue proliferation (Fig. 12, 13, and 14). Many of the remaining Purkinje cells showed an acute hyaline necrosis. These changes, disappearance of Purkinje cells and hyaline necrosis in a proportion of the remaining cells were also evident in the bundle branches (Fig. 15) where in addition a mononuclear cellular reaction surrounded some of the damaged

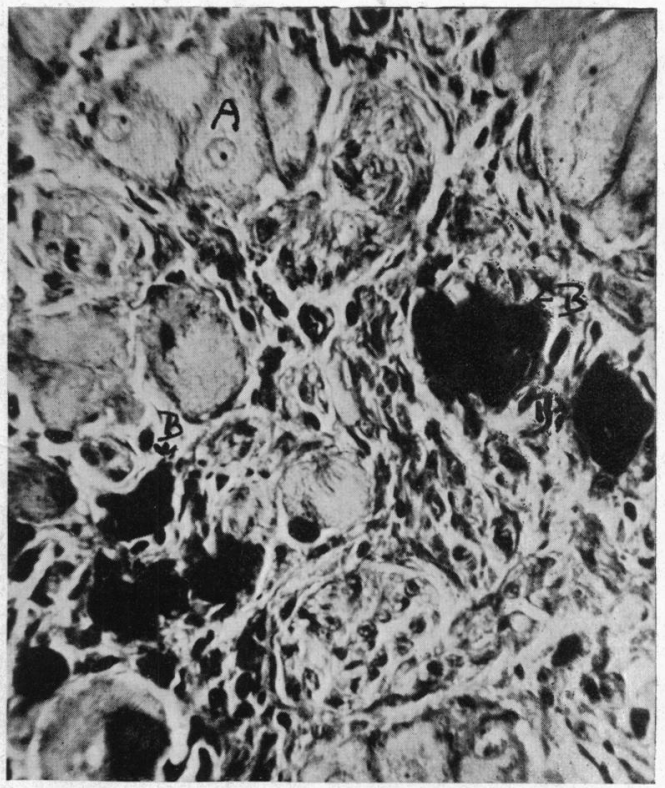

Fig. 10.-Pig No. 3. Bundle of His from the animal dying with complete heart block. There is an acute hyaline necrosis of many of the Purkinje cells. (A) Normal cells. (B) Necrotic cells. Magnification $\times 375$.

cells. The terminal subendocardial and intramyocardial ramifications of the Purkinje system throughout the ventricles of these two animals were grossly involved in both old and recent lesions. More than half the Purkinje cells showed recent necrosis with an associated marked mononuclear cellular reaction. In some sections complete interruption of a Purkinje strand by a cellular exudate was seen (Fig. 16).

Acute hyaline necrosis of the Purkinje cells was not found in the animal sacrificed after 157 days. Extensive healed lesions consisting of fibrous replacement of Purkinje cells were however found throughout the conducting system, and were particularly marked in the bundle branches.

\section{Discussion}

Records of the cardiovascular changes in experimental thiamin deficiency in animals are numerous. In thiamin deficient rats, Weiss et al. (1938) found marked bradycardia and changes in the $T$ waves and S-T segments; these changes usually disappeared within a few hours of giving thiamin, but were unaffected by atropine. Carter and Drury (1929) noted bradycardia and heart block in thiamin deficient pigeons. Swank and Bessey (1942) however, minimize the significance of bradycardia and heart block in pigeons since they found starvation 


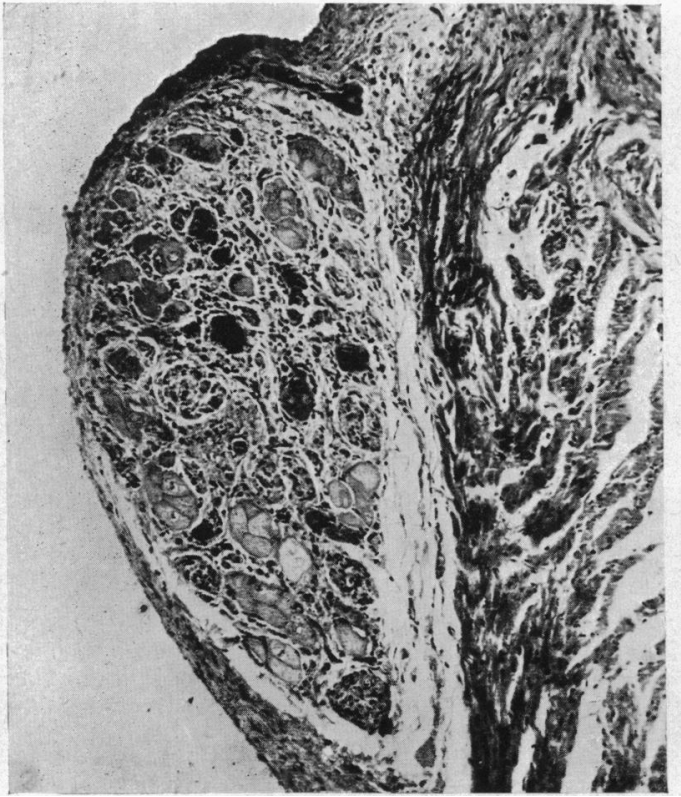

Fig. 11.-Pig No. 3. Left bundle branch showing acute hyaline necrosis of approximately onethird of the Purkinje cells with associated cellular reaction. Magnification $\times 75$.

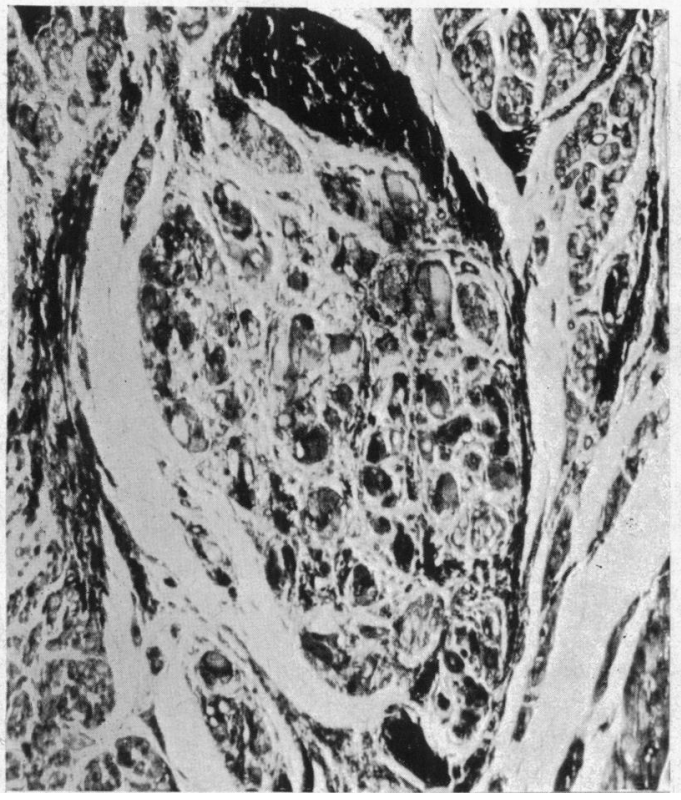

FIG. 13.-Pig No. 1. Bundle of His from an animal surviving 34 days after the occurrence of heart block, showing loss of Purkinje cells and their replacement by connective tissue. A number of the remaining cells show a hyaline necrosis. Magnification $\times 60$.

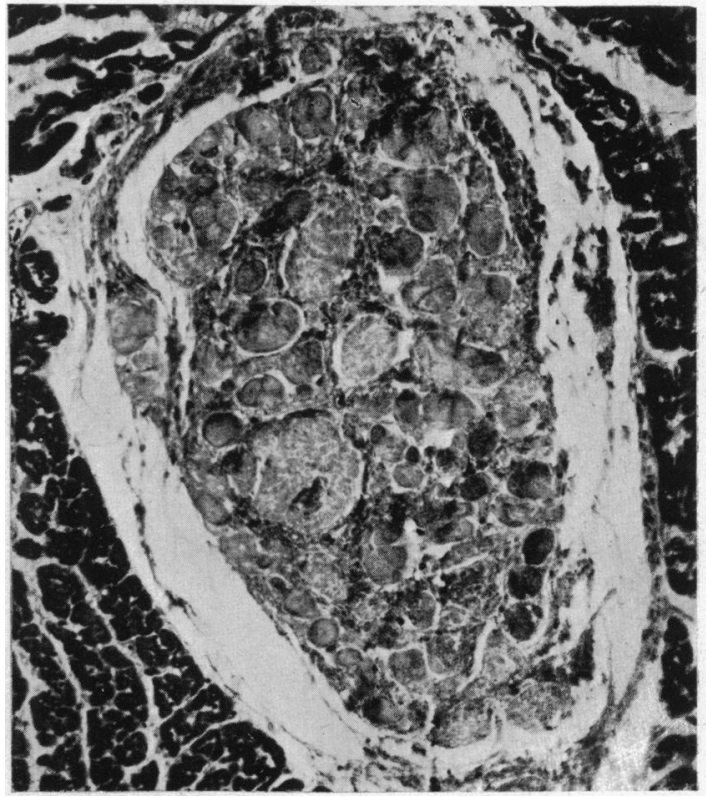

Fig. 12.-Bundle of His in a normal pig. Magnification $\times 60$.

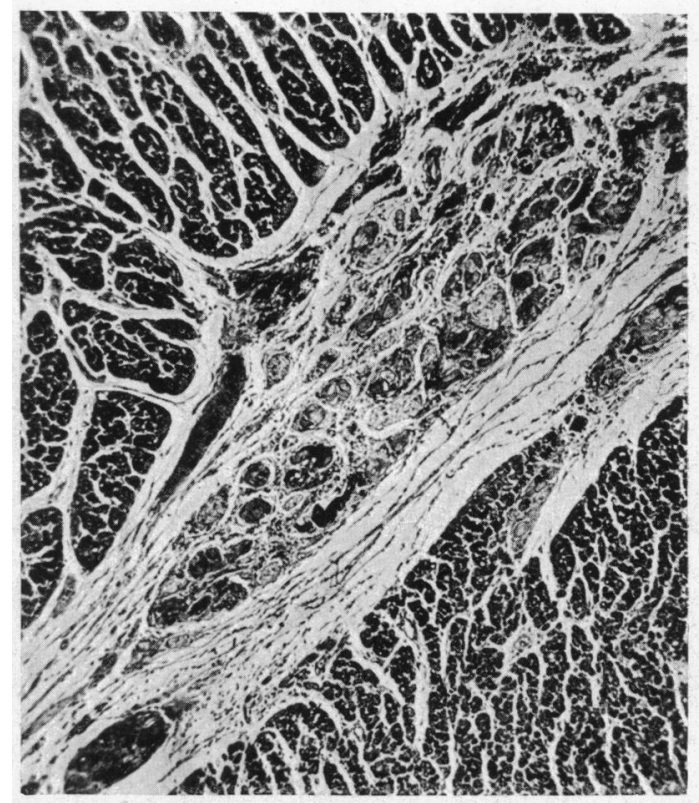

Fig. 14.-Pig No. 4. Bundle of His from an animal surviving 53 days after the occurrence of block. The changes are more marked than those in Fig. 13. Magnification $\times 40$. 


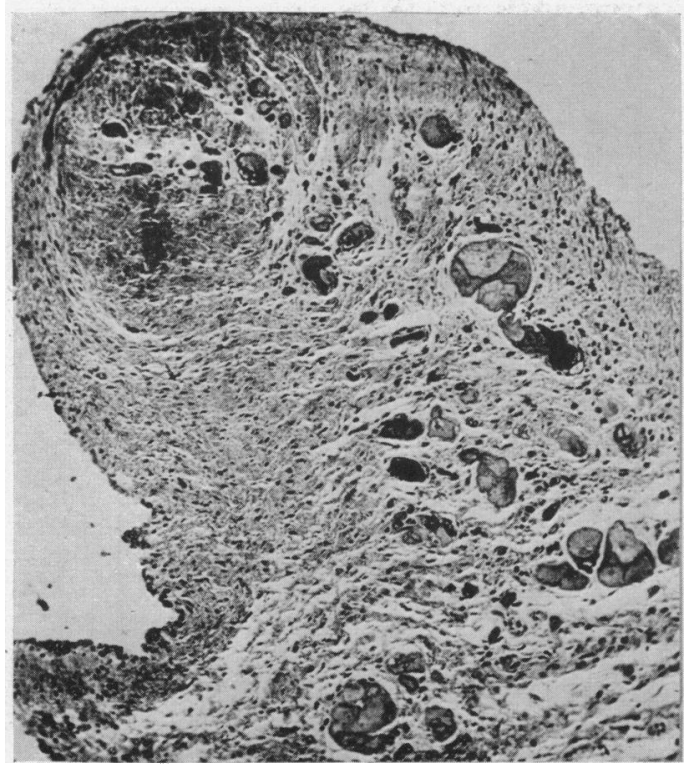

FIG. 15.-Pig No. 1. Terminal part of the left bundle branch showing loss of Purkinje cells and fibrosis surrounding surviving cells. Many of the remaining Purkinje cells show a hyaline necrosis. Magnification $\times 100$. alone would produce these effects: histological examination of the hearts of pigeons dead from chronic thiamin deficiency showed necrosis of the myocardial fibres associated with an inflammatory cell infiltration. De Soldati (1939) in thiamin deficient dogs noted high $\mathbf{P}$ waves and changes in the $T$ waves and $S-T$ segment.

In thiamin deficient pigs Wintrobe et al. (1943) recorded bradycardia, marked sinus arrhythmia, disturbances of $\mathrm{A}-\mathrm{V}$ conduction and changes in the $\mathrm{T}$ waves. Bradycardia was considered to be a more pronounced degree than could be accounted for by inanition. Eight of the nine pigs showed prolongation of the P-R interval, two developed second degree block, and one complete heart block. The most constant $T$ wave change was inversion of T IV. Atropine caused disappearance of a second degree heart block in one pig and in another shortening of the $\mathbf{P}-\mathbf{R}$ interval and return to normal of the inverted T IV. In both pigs atropine caused an increase in the heart rate. The lesions found at autopsy in these animals included cardiac hypertrophy and dilatation, cellular infiltration, and scarring, as well as fresh necroses in the auricles and ventricles.

King and Sebrell (1946) in experimental thiamin

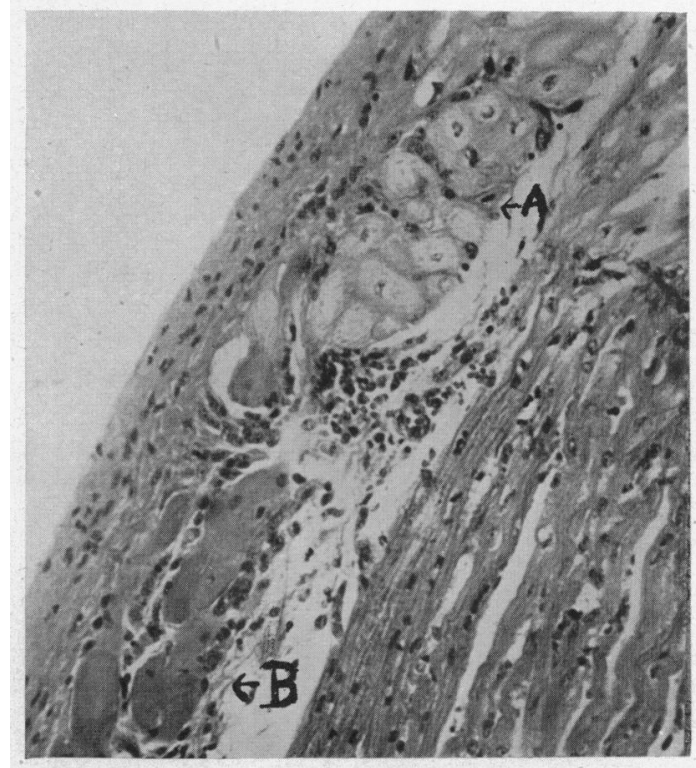

Fig. 16.-Pig No. 4. Subendocardial Purkinje strand anterior wall of left ventricle. (A) Normal cells. (B) Purkinje cells showing early hyaline necrosis associated with cellular infiltration. This cellular infiltration is seen to produce complete interruption of the Purkinje strand. Magnification $\times 165$.

deficiency in rats noted marked bradycardia, progressive widening of the $P-R$ interval and QRS complex and an increase in amplitude of QRS complex and of the T waves in leads II and III. Auricular fibrillation and A-V nodal rhythm were noted in some animals during episodes of acute deficiency. Fourteen of twenty-four experimental rats showed cardiac lesions at autopsy; in ten of these the lesions were predominantly auricular.

Ashburn and Lowry (1944) in a detailed pathological study of thiamin deficient in rats found a moderate to marked dilatation of the right auricle; in some hearts the left auricle was dilated, but to a much less degree, and an occasional heart showed dilatation of the right ventricle. Histological lesions in the auricles were found in 46 of the 58 , but ventricular lesions in only 7 of the deficient animals. The initial change consisted of a hyaline necrosis of the muscle cell associated with a cellular reaction consisting of neutrophils, lymphocytes, and mononuclear cells. There was ultimately disappearance of muscle fibres. Some of the acute lesions were followed by fibroblastic proliferation. The inactive lesions showed absence of muscle fibres and marked thinning of the auricular wall with some fibrosis. In a few instances there was a gross fibrosis of the 
auricular wall. Van Etten et al. (1940) in thiamin deficient pigs described myocardial lesions consisting of scattered areas of atrophy and necrosis of muscle suggestive of infarction. The lesions were particularly marked in the wall of the left ventricle.

Porto and de Soldati (1940) found dilatation of the right auricle in four dogs maintained on a thiamin deficient diet. Two also showed dilatation of the right ventricle. Histological examination showed dissociation of the muscle fibres by interstitial œdema, lack of clarity of the transverse striations, hydropic degeneration of the muscle cells, most marked in the conducting system and areas of hyalinization of muscle fibres associated with cellular infiltration. The lesions were found disseminated throughout the heart, but were most marked in the right auricle and right ventricle. Follis et al. (1943) studied the lesions in thiamin deficient pigs. The hearts of six of nine animals were dilated and showed lesions consisting of focal or diffuse necrosis of the myocardial fibres associated with leucocytic infiltration. In an animal dying, early lesions were found in the auricles, but none in the ventricles. Animals that survived longer periods of deficiency showed lesions on both auricles and ventricles. Scars marking healed necrotic lesions were found in the hearts of two animals.

Swank et al. (1941) in five dogs dead from thiamin deficiency found dilatation of the right auricle and right ventricle in one; the others showed marked dilatation of the left side of the heart. Histological study showed some general shrinkage, and pale indistinct staining of the muscle fibres in all hearts. In three hearts small scattered areas of myocardial necrosis were observed, many of which were infiltrated with polymorphonuclear leucocytes. One heart showed older lesions consisting of small areas of loose connective tissue from which myocardial fibres were absent.

From these accounts of animal experiments it is apparent that morphological lesions in the myocardium may result from thiamin deficiency. There is, however, no complete agreement as to their character of distribution. In the experiment recorded the finding of dilatation of the right side of the heart agrees with the observations of Porta and de Soldati (1940) and of Ashburn and Lowry (1944). The increase in heart-body weight ratio above the normal 0.3 to 0.4 per cent found in this experiment has been noted by Follis et al. (1943). These authors point out however that it cannot be concluded from this, that the hearts were hypertrophied since in the presence of impaired growth from causes other than thiamin deficiency there is an alteration in the heartbody weight ratio.

The preponderant involvement of the auricular myocardium in this study agrees with the findings of Follis et al. (1942) in pigs, and those of Ashburn and Lowry (1944) and of King and Sebrell (1946) in rats. It is probable that the sinus block observed in three of the animals was related to morphological lesions in the auricular wall since it was unaffected by atropine. In the one animal in which it never appeared lesions in the right auricle were minimal.

This predilection of the myocardial lesions of thiamin deficiency for the auricles suggests that the metabolism of the auricular and ventricular myocardium differs in some respects. A difference in their metabolism has been suggested by Davies and Francis (1946) on the basis of a difference in their intrinsic rhythmic rates. These authors write "In the hearts of cold blooded vertebrates in which there is neither specialized muscular tissue (nodal and Purkinje) nor any histological difference in the ordinary cardiac muscle which later nevertheless exhibit different intrinsic rhythms when separated from each other, their different rhythmicities must be dependent on factors other than purely morphological characters." Davies and Francis (1946) have attempted to discover whether substances known to be concerned in the chemistry of contraction of voluntary muscle are unevenly distributed throughout the heart. They have shown that glycogen, phosphocreatine and adenosine compounds have such a differential distribution.

It is notable that a morphological lesion is not suggested as the causative factor in those instances in which disturbances of auriculo-ventricular conduction have been found. Thus Swank and Bessey (1942) minimize the significance of heart block in pigeons since they found that it might result from inanition alone; and Wintrobe et al. (1943) found that heart block in thiamin deficient pigs responded to atropine.

The experiment recorded shows conclusively that heart block and morphological changes in the cells of the conducting system may result from thiamin deficiency. It would appear that initially the block is due to a reversible biochemical disturbance, and that this disturbance is capable of progression to an irreversible morphological change if acute deficiency is of sufficient duration. The presence of histological lesions in a proportion of the cells of the bundle of His in animals No. 1 and 4 suggest that cardiograms taken immediately before the death of these animals would have shown heart block.

The selective involvement of Purkinje tissue found in this experiment suggests that these cells have also a metabolism which differs from that of the ventricular myocardium. Consistent with this view are the observations of Shaner (1930) and of Davies and Francis (1941a). Shaner's studies in the ontogenetic 
development of this system in the calf suggests that Purkinje fibres and ordinary cardiac muscle are separately developed from their respective undifferentiated mesodermal primordia. Davies and Francis (1941 $a$ and 1946), have failed to demonstrate any nodal or Purkinje tissue in a number of fish, amphibia and reptiles, and express the opinion that the $\mathrm{S}-\mathrm{A}, \mathrm{A}-\mathrm{V}$ nodes, the A-V bundle and the terminal network of Purkinje fibres are neomorphic developments in animals and birds associated with the more rapid rate of heart in these homiothermal vertebrates.

The infrequency of heart block in human beriberi in contrast to the readiness with which it may be produced in experimental thiamin deficiency in pigs may be explained by the difference between the structure of the conducting system in man and that in ungulates. This difference has been stressed by Glomset and Glomset (1940).

The biochemical or morphological changes are most likely to be found in those cells of the conducting system in man that most closely resemble in structure the Purkinje cells in ungulates. The cells most closely resembling the Purkinje cells in ungulates are found in man at the terminal ramification of the conducting system beneath the endocardium of the ventricles. As the conducting system is traced back toward the A-V node the similarity diminishes. It has been noted that Glomset and Glomset found no cells resembling the Purkinje cells of sheep or pigs in the bundle of His in man.

In thiamin deficiency of moderate degree abnormalities of the ventricular complex of the cardio- gram probably result from changes in a proportion of the cells of the terminal ramifications of the conducting system.

It further follows that disturbances affecting conduction in the main branches of the bundle of His in beriberi would be of commoner occurrence than $\mathrm{A}-\mathrm{V}$ block. It is, therefore, of interest that in one of the few reports of cardiac conduction defects in beriberi, that of Dock (1940), three of five cases showed bundle branch block and one latent A-V block.

\section{SuMMARY}

The clinical impression of the not infrequent occurrence of auriculo-ventricular block in beriberi is recorded.

An experiment with the object of studying the effects of thiamin deficiency on cardiac conduction is described. Four pigs deprived of thiamin developed heart block; in two this was complete.

The histological lesions resulting from thiamin deficiency predominantly involve the auricular myocardium and the cells of the conducting system in the ventricles. In pigs dying from thiamin deficiency an acute hyaline necrosis is seen in the Purkinje cells.

I am indebted to Professor J. H. Biggart, C.B.E., and Dr. S. B. Boyd Campbell for the facilities that made this investigation possible. I wish to thank Professor Biggart for much advice and help in preparing this paper, and Dr. J. E. Morison for this valuable advice on the interpretation of the histological lesions. I am indebted to Mr. J. Harland for technical assistance and to Mr. D. McA. Mehaffey, A.R.P.S., for the photography.

\section{REFERENCES}

Aalsmeer, W. C., and Wenchebach, K. F. (1929). Wein. Arch. inn. Med., 45, 1.

Ashburn, L. L., and Lowry, J. V. (1944). Arch. Pathol., 37, 27.

Blankenhorn, M. A. (1945). Ann. intern. Med., 23, 398.

Carter, C. W., and Drury, A. N. (1929). J. Physiol., 68, 1.

Casanova, J. (1946). Algerie Med., 3, 203.

Davies, F., and Francis, E. T. B. (1946). Biol. Rev., 21, 173.

$-\frac{1}{-},(1941 a) . \quad$ Philos. Trans. B., 231, 99.

Dock, W. (1940). Trans. Ass. Amer. Phys., 55, 61.

Dustin, C. C., Weyler, H., and Roberts, C. P. (1939). New Engl. J. Med., 220, 15.

Van Etten, C., Ellis, N. R., and Madsen, L. L. (1940). J. Nutrit., $20,607$.

Follis, R. H., Jr., Miller, M. H., Wintrobe, M. M., and Stein, H. J. (1942). Amer. J. Path., 19, 341.

Glomset, D. J., and Glomset, A. T. A. (1940). Amer. Heart J., 20, 677.

Jolliffe, N., Goodhart, R., Gennis, J., and Cline, J. K. (1939). Amer. J. med. Sci., 198, 198.

Keefer, C. S. (1930). Arch. intern. Med., 45, 1.
King, W. D., and Sebrell, W. H. (1946). Pub. Health Rep. Wash., 61, 410.

Porto, J., and de Soldati, L. (1940). Rev. Soc. Argent. Biol., 15, 303.

Shaner, R. F. (1930). Anat. Rec., 44, 85.

de Soldati (1939). Rev. Soc. Argent. Biol., 15, 142.

Swank, R. L., Bessey, O. A. (1942). Arch. intern. Med., 70, 763.

- , Porter, R. R., and Yeomans, A. (1941). Amer. Heart J., 22, 154.

Weiss, S., Haynes, F. W., and Zoll, P. M. (1938). Amer. Heart J., 15, 206.

-_, and Wilkins, R. W. (1937). Ann. intern. Med., 11, 104.

Wenckebach, K. F. (1934). Das Beriberi-Herz: Morphologie, Klinik, Pathogenese. Pathologie und Klinik in Eingeldarst, Band VI. (Springer).

Wintrobe, M. M., Stein, H. J., Miller, M. H., Follis, R. H., Jr., Najjar, V., and Humphreys, S. (1942).

Bull. Johns Hopkins Hosp., 71, 141 .
- , Alcayaga, R., Humphreys, S., and Follis, R. H., Jr. (1943). Ibid., 73, 169. 